\title{
Optimization of Heat Gain by Air Exchange through the Window of Cold Storage Using Regression Analysis
}

\author{
Dr. Nimai Mukhopadhyay", Aniket Deb Roy ${ }^{* *}$ \\ ('Assistant professor, Department of Mechanical Engineering, Jalpaiguri Government Engineering College, \\ W.B. India) \\ (**Post Graduate scholar, Department of Mechanical Engineering, Jalpaiguri Government Engineering \\ College, W.B, India)
}

\begin{abstract}
Energy is at scarcity, crisis of energy is leading towards a world where growth might come to an absolute hold and optimizing the processes might give a way out to save energy for future generations and give some positive way out. In this situation if the maximum heat energy $(\mathrm{Q})$ is absorbed by the evaporator inside the cold room through convective heat transfer process in terms of -heat transfer due to convection and heat transfer due to condensation and also heat enter in the cold store due to air exchange through the windows more energy has to be wasted to maintain the evaporator space at the desired temperature range of 2-6 degree centigrade. In this paper we have tried to optimize the heat gain by the air exchange through the windows of cold storage in the evaporator space using regression analysis. Temperature difference (dT), Height of cold store Window $(\mathrm{H})$ and Relative Humidity $(\mathrm{RH})$ are the basic variable and three ranges are taken each of them in the model development. Graphical interpretations from the model justify the reality through regression analysis.
\end{abstract}

Keywords: Cold storage, Heat gain through windows, Regression analysis.

\section{INTRODUCTION}

India is a agro based country produces lots of different types of agro based products, but these products has got a shelf life which restricts its availability throughout the year, this is the position where cold storages play a vital role they help us to increase the shelf life of the agro products not only agro based products marine products are also produced in large amount. The cold storage facilities are one of the prime infrastructural requirements for perishable commodities it helps to in availability of a product throughout a year .Besides the role of stabilizing market prices and evenly distributing both on demand basis and time basis, the cold storage industry provide other advantages and benefits to both the farmers and the consumers. The farmers get the opportunity to get a good return for their hard work. On the consumer sides they get the perishable commodities with lower fluctuation of price. Very little theoretical and experimental studies are being reported in the journal on the performance enhancement of cold storage. Energy crisis is one of the most important problems the world is facing nowadays. With the increase of cost of electrical energy operating cost of cold storage storing is increasing which forces the increased cost price of the commodities that are kept. Thus the storage cost will eventually go up. In convection maximum heat should be absorbed by refrigerant to create cooling uniformity throughout the evaporator space. If the desirable heat is not absorbed by tube or pipe refrigerant then temperature of the refrigerated space will be increased, which not only hamper the quality of the product which has been stored there but reduces the overall performance of the plant. But also the heat enters in the cold store due to infiltration through cold room doors and windows. In this case we are considering the infiltration through the windows. Fresh air charge is required for the commodities kept in the cold storages but whenever this fresh air enters the cold store room it increases the temperature of the cold storage room which creates a load on the cooling device and extra consumption of energy takes place.

In this paper we have proposed a modified mathematical heat transfer model of convective heat transfer in the evaporator space and heat enter in the cold store due to infiltration through cold room windows using Taguchi L9 orthogonal array as well as Taguchi L18 orthogonal array. Relative humidity (RH), Temperature difference (dT), Height of cold store window $(\mathrm{H})$ are the basic variable and three ranges are taken each of them in the model development. 


\section{LITERATURE REVIEW}

Types of Cold Storages

Cold storages are classified in different ways as indicated below.

\section{Classification based on the use of cold store}

- Milk cold storage

- Cheese cold storage

- Butter cold storage

- Potato cold storage etc.

The storage conditions to be maintained as well as method of storage for these cold storages vary depending on the optimum storage conditions required for different products. For example, cheddar cheese is stored at around $10{ }^{\circ} \mathrm{C}$ and $90 \%$ relative humidity for ripening of cheese. Appropriate method of storage of product is very important aspect. Racks are required to keep cheese blocks in the cold storages.

\section{II.I.Classification based on operating temperature of cold storage \\ - Cold storage maintained above $0^{\circ} \mathrm{C}$ \\ - Cold storage maintained below $0{ }^{\circ} \mathrm{C}$}

Milk cold storage is maintained above ${ }^{\circ} \mathrm{C}$ while ice-cream cold storage is maintained below 0 ${ }^{\circ} \mathrm{C}$. Product load is one of the factors for estimation of cold storage load. It is necessary to calculate heat to be removed from the product when a part of water gets frozen at storage temperature of the product. The design of evaporator, air circulation, expansion valve etc. will be different in these cold storages. The thickness of insulation required for low temperature cold storage will be more to reduce the wall gain load.

\section{II.II.Classification based on the construction}

- Constructed cold storage

- Walk in cold storage

Mostly cold storage is constructed in dairy building as per the design and layout of the dairy plant. The cold storage is generally constructed by civil work and insulated either by Thermocoil sheets or PUF panels.

\section{II.III.Types of Loads in Cold Storages}

It is basic requirement to know the types of loads in the specific cold storage in order to find the capacity of the refrigeration system for the cold storage. It is necessary not only to cool the product to the storage temperature but also to meet the cooling load due to various heat infiltrations taking place in the cold storage. Broadly, the total load is divided into two categories as under.

\section{II.IV.Sensible heat load}

- Heat flow through walls, ceilings, floor, doors (structural heat gain).
Heat gain from infiltration of air due to door openings and movement of products through opening provided in the walls. For example, crates of milk enter in the milk cold storage through a gap provided in the wall using conveyer. This load is kept minimum by using appropriate strips of flexible plastic sheets to reduce the exchange of air. - Heat received by workers working in cold storage. Though, it is very small as number of persons working in the cold storage is very few. This load is very important in air conditioning system as it is for providing comfort to large number of occupant.

- Heat load due to lighting and other motors used in the cold storage.

II.V.Latent heat load

- Latent heat load from infiltration of air.

- Latent heat load from occupancy.

- Latent heat generated from the stored products.

Based on the above heat load, the actual amount of heat flow rate is calculated in order to find total load to decide the capacity of evaporator of the refrigeration plant.

Our main objective of this project is to optimize infiltration load through windows so we will see the effect of heat transfer due to air exchange from different openings of cold storage specifically windows.

\section{MATHEMATICAL MODEL DEVELOPMENT}

In this study heat transfer in the evaporator space of the cold store and also heat enter in the cold store due to infiltration through cold room windows both are considered. Heat transfer in the evaporator space of the cold store and also heat enter in the cold store due to infiltration through cold room windows both are calculated in terms of velocity of air (V), temperature difference (dT) and height of the cold store window $(\mathrm{H})$. On both occasion heat is transferred through convective heat transfer process. Inside the cold storage there are many numbers of windows the store we are considering have eight numbers of windows, four in each chamber.The equation of heat transfer is given below:

$\mathrm{QT}=\mathrm{Q}_{\text {conv }}+\mathrm{Q}_{\text {condensation }}$.
$\mathrm{Q}_{\text {conv }}=\mathrm{AhcdT} \& \mathrm{Q}_{\text {condensation }}=\mathrm{Ah}_{\mathrm{m}}(\mathrm{RH}) \mathrm{hf}_{\mathrm{g} .}$.

Here,

$* \mathrm{Q}_{\text {conv }}=$ heat transfer due to convection

* $\mathrm{Q}_{\text {condensation }}=$ heat transfer due to condensation

* $\mathrm{Q}_{\mathrm{T}}=$ Total heat transfer or absorbed heat into refrigerant.

$\mathrm{H}_{\mathrm{c}} \mathrm{k} / \mathrm{L}=\mathrm{Nu}$ 
Then the final equation will become:

$\mathrm{Q}_{\mathrm{T}}=(0.322 * \mathrm{H} * \mathrm{dT})+(352.39 \mathrm{RH})$

Where,

*A=surface area of tubes in evaporator space 1872 $\mathrm{m}^{2}$

$* \mathrm{~h}_{\mathrm{c}}=$ convective heat transfer co-efficient.

$* \mathrm{~h}_{\mathrm{m}}=$ convective mass transfer co-efficient

$* \mathrm{~h}_{\mathrm{fg}}=$ latent heat of condensation of moisture 2490 $\mathrm{KJ} / \mathrm{Kg}-\mathrm{K}$

\section{III.I.REGRESSION ANALYSIS}

Regression analysis is the relationship between various variables. By regression analysis we can construct a relationship between response variables and predictor variables. It demonstrates what will be the changes in response variable because of the changes in predictor variable. Simple regression equation is $y=a+b x$. In this problem more than one predictor variable is involved and hence simple regression analysis cannot be used. We have to take the help of multiple regression analysis. There are two types of multiple regression analysis- 1) Simple multiple regression analysis (regression equation of first order) 2) Polynomial multiple regression analysis (regression equation of second order or more) Simple multiple regression analysis is represented by the equation of first order regression:

$\mathbf{Y}=\square_{0}+\square_{1} \mathbf{X}_{1}+\square_{2} \mathbf{X}_{2}+\square_{3} \mathbf{X}_{3}+\ldots \ldots \ldots \ldots \ldots \ldots \ldots . . .+\square$.
Where $\beta$ is constant terms $\& \mathrm{X}$ is the variables $\& \varepsilon$ is the experimental error. Polynomial multiple regression analysis equation is:

$$
\begin{aligned}
& \mathbf{Y}=\square_{0}+\square_{1} \mathbf{X}_{1}+\square_{2} \mathbf{X}_{2}+\square_{3} \mathbf{X}_{3}+\square_{11} \mathbf{X}_{211}+\square_{22} \mathbf{X}_{222}+\square_{33} \mathbf{X} \\
& { }_{233}+\square_{12} \mathbf{X}_{1} \mathbf{X}_{2}+\square_{13} \mathbf{X}_{1} \mathbf{X}_{3}+\square_{23} \mathbf{X}_{2} \mathbf{X}_{3} .
\end{aligned}
$$

The above equation is second order polynomial equation for 3 variables. Where $\beta$ are constant, $X_{1}$, $\mathrm{X}_{2}, \mathrm{X}_{3}$ are the linear terms, $\mathrm{X}_{12} \mathrm{X}_{13} \mathrm{X}_{23}$ are the interaction terms between the factors, and lastly $\mathrm{X}_{11}$ $\mathrm{X}_{22} \mathrm{X}_{33}$ are the square terms.

Here we will have to calculate the values of $\square_{0}$, $\square_{1}, \square_{2}, \ldots . .$. . up to $\square_{9}$. There are 10 variables and nine equations so we will have to find one more equation to complete the matrix format required for the purpose of solving the following equation. All the nine equations will be taken by using Taguchi's L9 orthogonal array and the last equation is taken from

L18 orthogonal array. Here are the given formats of the L9 and L18 orthogonal array.

\section{TABULATION}

Now the L9 orthogonal array and L18 orthogonal array is given which is required for the purpose and we will fit the data in the following pattern to solve the particular problem.

\begin{tabular}{|l|l|l|l|l|l|}
\hline c & Factors & Units & \multicolumn{3}{|l|}{$\begin{array}{l}\text { Levels of Experimental } \\
\text { Data }\end{array}$} \\
\hline H & $\begin{array}{l}\text { Height of the } \\
\text { window }\end{array}$ & $\mathrm{m}$ & 1 & 1.25 & 1.5 \\
\hline dT & $\begin{array}{l}\text { Temperature } \\
\text { difference }\end{array}$ & Centigrade & 2 & 4 & 6 \\
\hline RH & $\begin{array}{l}\text { Relative } \\
\text { Humidity }\end{array}$ & $\%$ & 85 & 90 & 95 \\
\hline
\end{tabular}

These are the data's collected experimentally for the purpose from the cold storage. Here Height of the window is taken in $\mathrm{m}$, temperature difference in centigrade and relative Humidity in \%.

Now we will have to use these values and design the required array for the purpose.

\begin{tabular}{|l|l|l|l|}
\hline Test Runs & H & dT & RH \\
\hline 1. & 1 & 2 & 85 \\
\hline 2. & 1 & 4 & 90 \\
\hline 3. & 1 & 6 & 95 \\
\hline 4. & 1.25 & 2 & 90 \\
\hline 5. & 1.25 & 4 & 95 \\
\hline 6. & 1.25 & 6 & 85 \\
\hline 7. & 1.5 & 2 & 95 \\
\hline 8. & 1.5 & 4 & 85 \\
\hline 9. & 1.5 & 6 & 90 \\
\hline 10. & 1.5 & 4 & 85 \\
\hline
\end{tabular}



ISSN : 2248-9622, Vol. 7, Issue 1, ( Part -4) January 2017, pp.40-45

In this table the last row is taken from L18 orthogonal array to make the calculation feasible.

\begin{tabular}{|l|l|l|}
\hline $\mathrm{H}$ & $\mathrm{dT}$ & $\mathrm{RH}$ \\
\hline 1 & 2 & 0.85 \\
\hline 1 & 4 & 0.9 \\
\hline 1 & 6 & 0.95 \\
\hline 1.25 & 2 & 0.9 \\
\hline 1.25 & 4 & 0.95 \\
\hline 1.25 & 6 & 0.85 \\
\hline 1.5 & 2 & 0.95 \\
\hline 1.5 & 4 & 0.85 \\
\hline 1.5 & 6 & 0.9 \\
\hline 1.5 & 4 & 0.85 \\
\hline
\end{tabular}

\section{CALCULATIONS}

$\mathrm{Q}_{1}=0.322(1) *(2)+(352.39 * 0.85)=300.1755 \mathrm{KJ}$

$\mathrm{Q}_{2}=0.322(1) *(4)+(352.39 * 0.90)=318.448 \mathrm{KJ}$

$\mathrm{Q}_{3}=0.322(1) *(6)+(352.39 * 0.95)=336.712 \mathrm{KJ}$

$\mathrm{Q}_{4}=0.322(1.25) *(2)+(352.39 * 0.90)=317.956 \mathrm{KJ}$

$\mathrm{Q}_{5}=0.322(1.25) *(2)+(352.39 * 0.90)=336.380 \mathrm{KJ}$

$\mathrm{Q}_{6}=0.322(1.25) *(6)+(352.39 * 0.85)=301.946 \mathrm{KJ}$

$\mathrm{Q}_{7}=0.322(1.5) *(2)+(352.32 * 0.95)=301.946 \mathrm{KJ}$
$\mathrm{Q}_{8}=0.322(1.5) *(4)+(352.39 * 0.85)=320.058 \mathrm{KJ}$

$\mathrm{Q}_{9}=0.322(1.5) *(6)+(352.39 * 0.90)=301.472 \mathrm{KJ}$

$\mathrm{Q}_{10}=0.322(1.5) *(4)+(352.39 * 0.85)=301.472 \mathrm{KJ}$

The basic equation to calculate $\mathrm{Q}$ is

$\mathbf{Q}=\square_{0}+\square_{1}(\mathbf{X})+\square_{2}(\mathbf{d T})+\square_{3}(\mathbf{H})+\square_{11}(\mathbf{X}) *(\mathbf{X})+\square_{22}(\mathbf{d}$ $\mathrm{T}) *(\mathrm{dT})+\square_{33}(\mathrm{H}) *(\mathrm{H})+\square_{12}(\mathrm{X}) *(\mathrm{dT})+\square_{13}(\mathrm{X}) *(\mathrm{H})+$ $\square_{23}(\mathrm{dT}) *(\mathrm{H})$

We get nine equations but numbers of unknowns are ten. Now we can solve these equationseliminate some of variables in terms of others. Then we get $[\mathrm{X}]$ matrix as [9*9]. We also get response variable matrix [Q] which is a [9*1] matrix. With the help of following equation we can get the co efficient values-[$[\beta]=[\mathrm{Q}]^{*}\left[\mathrm{X}^{-1}\right]$ where [x] - denotes the variable matrix. The proposed theoretical mathematical model for heat transfer through the window is

$\mathrm{Q}=3056+(2390 * \mathrm{H})+(298 * \mathrm{dT})+(11905 * \mathrm{RH})+(450$ $\left.* H^{2}\right)+\left(7 * \mathrm{dT}^{2}\right)+\left(1138 * \mathrm{RH}^{2}\right)+(113 * \mathrm{HdT})+(4535 * \mathrm{H}$ $* \mathbf{R H})+(-567 * \mathrm{dT} * \mathbf{R H})$

This equation is calculated via means of matlab through which $\square$ values are calculated.

\section{GRAPHS}

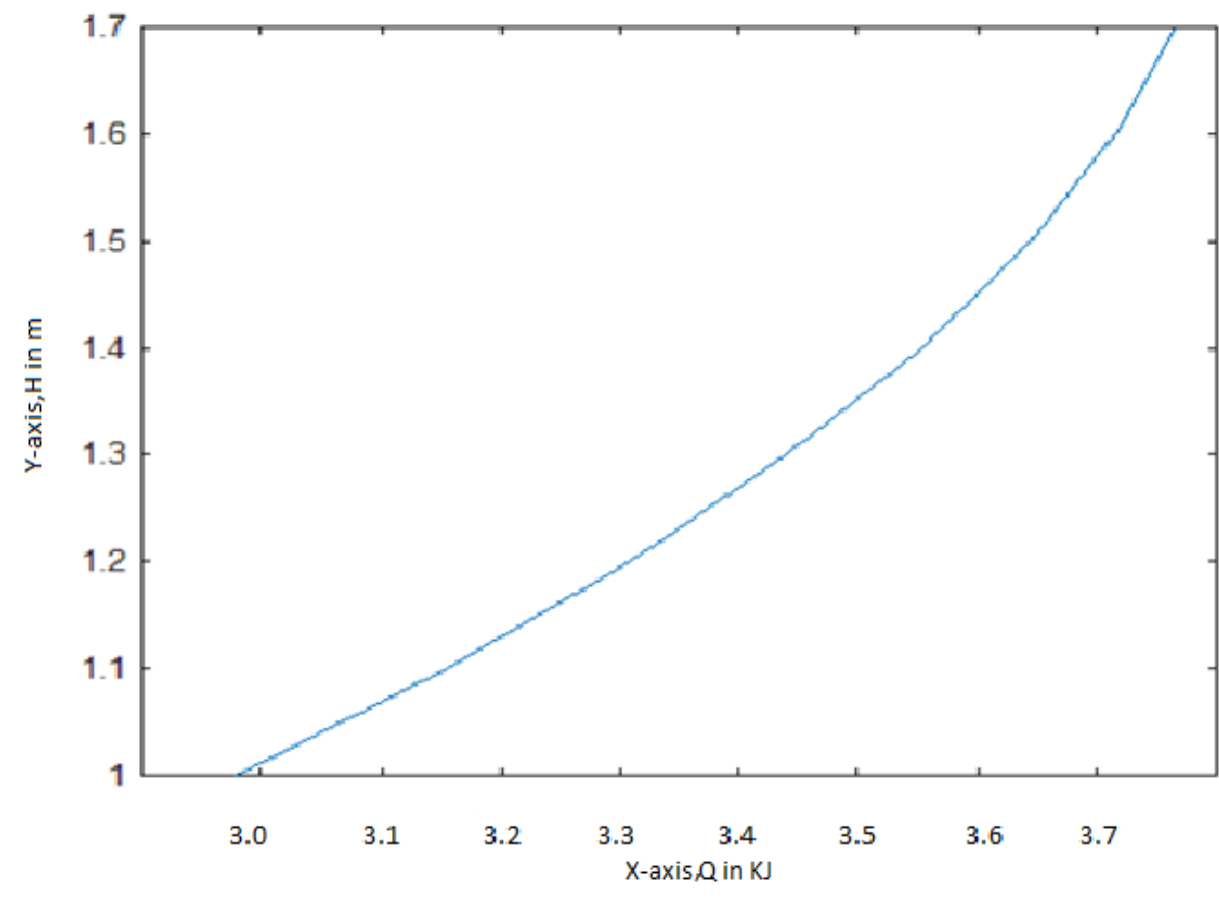

H vs. Q

Here the $\mathrm{X}$ axis is $\mathrm{Q}$ and the $\mathrm{Y}$ axis is $\mathrm{H}$. 

ISSN : 2248-9622, Vol. 7, Issue 1, ( Part -4) January 2017, pp.40-45

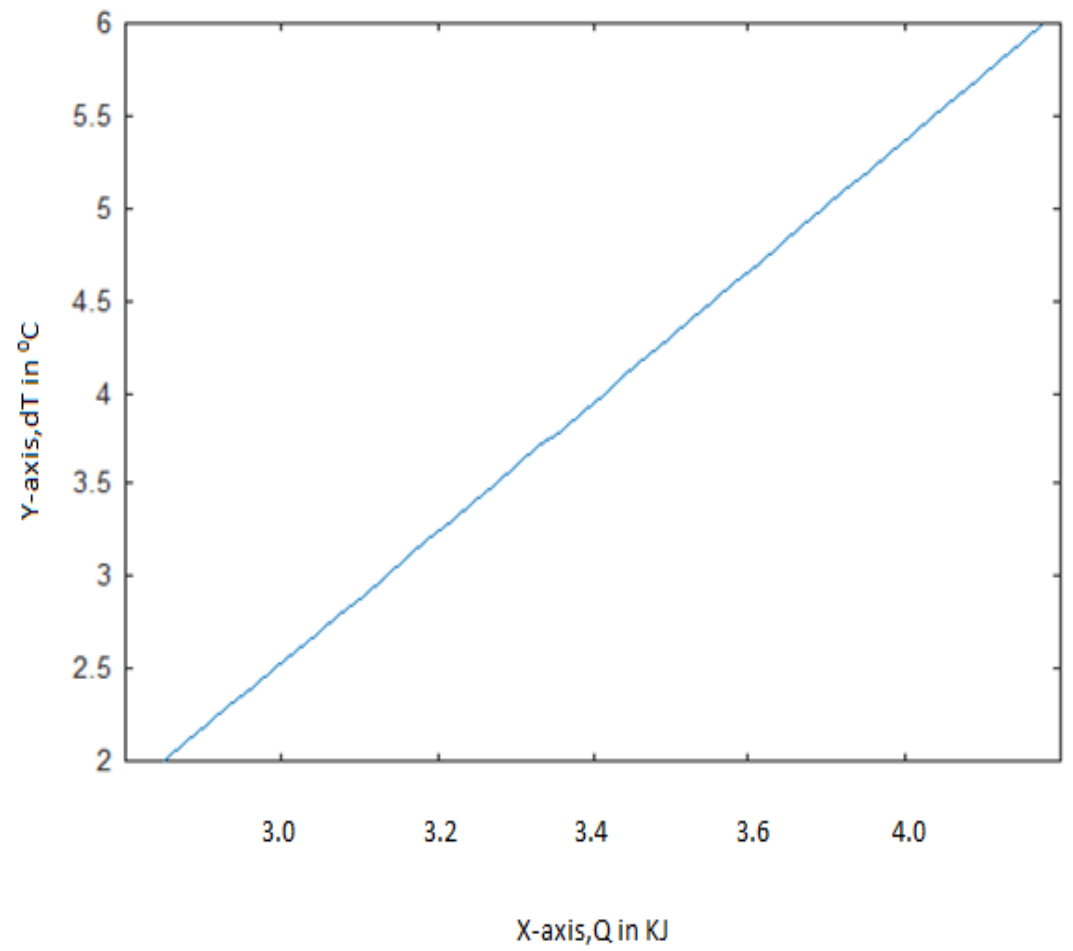

dT vs. Q

Here $\mathrm{Q}$ is $\mathrm{X}$ axis and $\mathrm{dT}$ is $\mathrm{Y}$ axis.

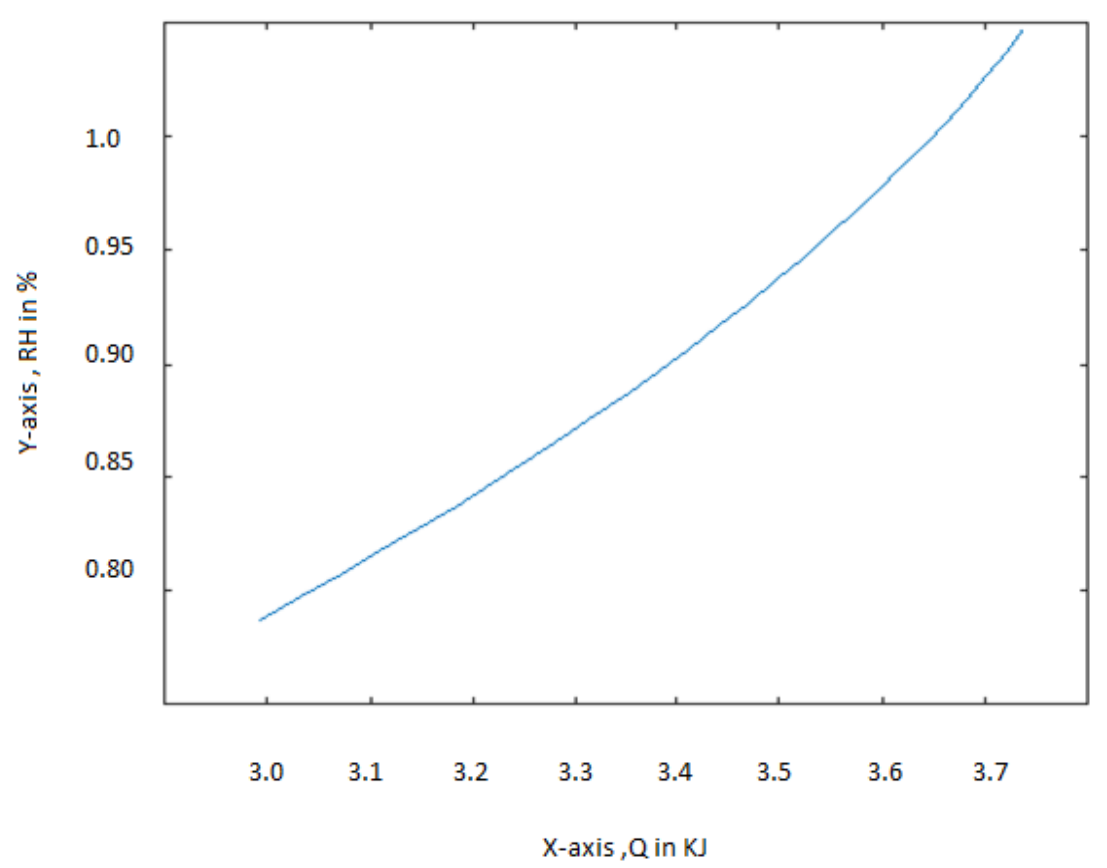

RH vs. Q

Here $\mathrm{Q}$ is $\mathrm{X}$ axis and $\mathrm{RH}$ is $\mathrm{Y}$ axis. 


\section{CONCLUSION}

1. From the analysis the optimal setting is recorded as $\mathrm{H}=1, \mathrm{dT}=2$ and $\mathrm{RH}=0.85$ and the values $\mathrm{H}=1, \mathrm{dT}=6, \mathrm{RH}=0.95$ are out of proportion hence eliminated.

\section{REFERENCE}

[1]. Dr. N. Mukhopadhyay, Suman Debnath, "OPTIMIZATION OF CONVECTIVE HEAT TRANSFER MODEL OF COLD STORAGE USING TAGUCHI S/N RATIO AND ANOVA ANALYSIS" ISSN: 23208163, www.ijtra.com Volume 3, Issue 2 (Mar-Apr 2015), PP. 87-92

[2]. Gosney, W.B. and Olama, H.A.L. Heat and enthalpy gains through cold room doorways. Proc. Inst. of Refrig. 1975:72; 31-4

[3]. Cold storage of food, Review of available information on energy consumption and energy savings options by Judith Evans.

[4]. Dr. N. Mukhopadhyay ,RajuDas"Optimization of Different Control Parameters of a Cold Storage using Taguchi Methodology"AMSE JOURNALS -2014Series: Modeling D; Vol. 36; $N^{\circ} 1 ;$ pp 1-9 Submitted July 2014; Revised Jan. 12, 2015; Accepted Feb. 20, 2015

[5]. Dr.NimaiMukhopadhyay," Theoretical Study of Heat Load Calculation of a Cold Storage System" Proc. 6th.WMVC-2014, November 1-3, $2014 \quad 52$ Siliguri (Darjeeling)pp.52-

57.email:nm1231@gmail.com

[6]. Dr. N Mukhopadhyay, Priyankar Mondal, "Optimization of Combined Conductive and Convective Heat Transfer Model of Cold Storage Using Taguchi Analysis" Int. Journal of Engineering Research and Applications www.ijera.com ISSN: 22489622, Vol. 5, Issue 11, (Part - 4) November 2015, pp.15-19

[7]. Prof. N. Mukhopadhaya, Raju Das,"Theoretical heat conduction model development of a Cold storage using Taguchi Methodology",International Journal Of Modern Engineering Research (IJMER), | Vol. 4 | Iss. 6| June. 2014, ISSN: 2249-6645
2. The maximum effect is rendered by the height of the windows on the $\mathrm{Q}$ of the system after that RH is the second leading factor, the less effective factor is the temperature difference dT. 